\title{
İki Şafak Arasında Etik ve Ahlak: Selman Nacar'la Filmlerindeki İkilemlere Dair Söyleși
}

Feride Çiçekoğlu*, Selman Nacar**

"Yirmili yaşlarında Kafka zaten Kafka'ydı." The New Yorker dergisinin 1 Haziran 2021 sayısında yazar Ben Okri'nin Kafka'ya atıfla söylediği bu cümle Reflektif dergisinin “Gündelik hayatta etik ve ahlak" konulu beşinci sayısı için Temmuz 2021'de yaptığı çağrıyı okurken zihnimde yönetmen Selman Nacar'ın film yapma serüveni ile birlikte yankılandı. Selman'ı tam on yıldır tanıyorum; İstanbul Hukuk Fakültesi'nden İstanbul Bilgi Üniversitesi Hukuk Fakültesi'ne yeni geçtiği ve seçmeli bir ders arayışıyla Santral E1-212'deki odamın kapısını çaldığı 2011 yılının o sonbahar gününden beri. Henüz lise öğrencisi olan ama daha o zamandan kısa filmleriyle dikkat çeken Burak Çevik'in de tam o sırada benim odamda olması ve sonradan uzun bir yolculuğun başlangıcına işaret eden tanışmanın orada ayaküstü gerçekleşmesi tesadüf sözcüğüyle açıklanabilir mi, yoksa daha mistik yorumlara açık hikayeler mi çağrıştırır, kuşkusuz bu söyleşinin kapsamı dışında. Sonuçta Selman’ın Bilgi'de hukuk ve sinema bölümlerini birlikte okuduğunu, mezuniyet sonrası sinemada karar kılıp Columbia Üniversitesi’nden yönetmenlik üzerine yüksek lisans derecesi aldığını hızlıca araya sıkıştırıp Okri’nin sözüne dönecek olursak, 2021'in Eylül ayında San Sebastian Fesitvali'nde ilk gösterimini yapan ve şimdiden pek çok ödülün sahibi olan Selman'ın ilk uzun metraj filmi İki Şafak Arasında ile ilk kısa filmi Киyu (2015) arasındaki ortak temaların etik ve ahlak olduğunu, özetle “Selman'ın yirmili yaşlarında zaten Selman olduğunu” onu tanıdığım ilk on yıla bakarak rahatlıkla söyleyebiliyorum.

Üniversitenin ilk yıllarında yaptığı bölümler arasındaki yolculuğun Selman'ın özünde var olan bir arayıştan, etik ve ahlak arasındaki çetrefilli ilişkilere, bireyle toplum arasındaki gri alanlara dair bir meraktan kaynakladığını kendisi de İki Şafak Arasında filmi için yaptığı pek çok söyleşide vurguluyor. Etik, ahlak ve hukuk arasındaki etkileşim, çelişki ve çatışmanın

* İstanbul Bilgi Üniversitesi, feride.cicekoglu@bilgi.edu.tr, ORCID: 0000-0003-3053-6853.

**nnacar.selman@gmail.com 
hukuk okuduğu için ilgi alanına girmediğini, bu soruların onu hukuk okumaya yönlendirdiğini ve sonrasında film yaparak hikaye anlatma serüveniyle tanıştı̆̆ında rotasını o yöne çevirdiğini anlatıyor. Selman henüz uluslararası platformlarda söyleşiler vermeden önce Reflektif için aşağıdaki söyleşiyi yaptığımızda İki Şafak Arasında ne San Sebastian'da ne de Antalya Altın Portakal Film festivalinde gösterilmişti. Filmin Antalya'da aldığı ödüller arasında bana da Cahide Sonku ödülü henüz verilmemiş̧i. Aşağıdaki söyleşi bütün bunlardan önce yapıldı. Şimdi yeniden okurken, sadece iki mevsim önce değil de yıllar önce yapılmış gibi hissediyorum. Girizgahı daha fazla uzatmadan sizi o söyleşinin masumiyeti ile baş başa bırakıyorum. ${ }^{1}$

Yirmili yaşlarındaki genç bir yönetmen olarak mezuniyet projesi üzerine düşünürken dahi Selman kendi ruhunun derinliklerine, peşini bırakmayan soruların karanlık sularına dalmış gibiydi; bu açıdan ilk filmindeki ana karakterin Anadolu'nun çorak toprakları ortasında suya ulaşmak için bir kuyu kazıyor olmasına şaşmamak gerek. Bu karakterin kişisel arzusu ile geleneğin dayatması arasındaki çatışma sonucu filmin sonunda kuyunun dibine salınan o haykırışı öyle bir sinemasal gücü vardı ki seyirci olarak bağıran sanki bizmişiz gibi sarsılıyorduk. Bu açıdan Selman'ın ilk uzun metrajı daha üstü kapalı, ana karakterin çıkmazı o denli güçlü bir duygu patlamasında ifade bulmuyor, fakat bu zımni anlatım yine de acı veriyor, çünkü o dügümü sessizce kabulleniyoruz ve yine benimseyip içimize gömüyoruz.

Henüz başında olduğu yönetmenlik kariyerinde neyin iyi, doğru, değerli, hakkaniyetli, adil ve meşru olduğuna dair alttan alta akıp giden düşünceler silsilesini su yüzüne çıkarabilmek üzere Selman'la aşağıdaki sorular üzerinden ilerledik. Cevaplardan çok soruların tetiklediği yeni soruları önemsedik. Bu söyleşinin Selman'ın şu anki yönetmenlik macerasına düşülmüş bir dipnot olmasını ve kariyerinin ileriki aşamalarında her on yıl dönümünde geriye bakıp bir tür ölçü çubuğu gibi görebileceği bir referans noktası, bir tür röper olmasını umduk.

Selman'ın kendi anlattı̆̆ı hikayelere mesafe alıp onlara dair analitik olarak da düşünebilme yeteneği sadece aynı zamanda hukukçu olmasından kaynaklanmıyor; bu yeteneğini aynı zamanda önce Uşak'tan İstanbul'a ve sonra İstanbul'dan New York'a taşınıp her iki metropolün de hem içerisinde hem dışarısında olabilmesine, kendisinin geçmişteki hallerine de mesafe alabilmesine, bunu yapabilecek psikolojik ve felsefi bir derinliğe de sahip olmasına borçlu. Yirmili yaşlarının ilk yarısını İstanbul'da, ikinci yarısını New York'ta yaşarken, değişen kültürel çevreye bağlı olarak etik ile ahlak arasındaki referansların nasıl değişebildiğini gözlemlemesi kendi konumunu sorgulayabilmesi için ona eşsiz fırsatlar sunmuş ve Selman tüm bu fırsatları farklı bakış açılarını yargılamaktansa anlayabilme çabasıyla değerlendirmiş. Aşağıdaki sorular onun bu yolculuğunun Temmuz 2021 itibarıyla sunduğu ipuçlarına notlar düşüyor.

\section{Çift meslekli yolculuk nasıl başladı, oradan başlayalım mı? Neden hukuk? Neden sinema? Her ikisinin film yapma macerasına etkileri nasıl oldu?}

İdealist bir genç olarak, edineceğim hukuk bilgisiyle toplumda bir değişim sağlayabileceğimi, daha adil ve huzurlu bir yaşam için çabalamamın vazifem olduğuna inanıyordum. Ancak, 
sinemayı meslek olarak yapmaya karar verdiğim ana kadar içimde tarif edemediğim büyük bir boşluk vardı. Yıllarca bunun arayışında şehirler, ülkeler ve üniversiteler değiştirdim. Sinema ile tanıştığımda ise bu boşluk amasız, birden ve kesin bir şekilde doldu. Büyük şehirlerde yaşayanlar film setlerine aşina olabilir ancak Uşak'ta büyümüş biri olarak hayatımda ilk defa bir film setini üniversiteye başladığımda, Galata'da yürürken gördüm. Sinemanın birçok sanat dalından beslenmesi, felsefi arka planı ve organizasyona dayalı saha yönüyle kişiliğimi tam olarak yansıtan bir meslek olduğunu hissettim ve sizin kapınızı çaldım. Sonrasında bahsettiğiniz gibi hem hukuk hem sinema eğitimime devam ettim. Aynı zamanda çalışıyordum. Zor bir süreçti. Kampüste oturup kahve içecek zaman pek bulamadım. Üniversitenin üçüncü senesinde Kuyu'yu çektim. Columbia'dan da yüksek lisans kabulü alınca orada devam ettim. Columbia'nın üçüncü senesinde de İki Şafak Arasında'yı (İŞA) çektim. Bu anlamda okul hiçbir zaman beni kısitlayan bir yer olmadı, hayatla birlikte devam etti.

İlk başlarda hukuk kimliğimi açık etmekten çok rahatsız oluyordum. Sadece sinemacı olarak anılmak istiyordum. Bu yüzden de yazdı̆̆ım şeylerde hep bundan kaçındım. İŞA'ya kadar yaptığım beş kısa filmde farklı denemeler yaptım. Galiba kendimle daha barışık bir hale geldim ki, IŞA'nda da hukuk-ahlak meselesi filmin temeline yerleşti. Şu anda yazdığım Tereddüt Çizgisi'nin ana karakteri de bir ceza avukatı. Ama hukuk eğitiminin katkısının daha çok analitik düşünme yetisi kazanmam olduğunu söyleyebilirim. Film çekerken hayal ettiğiniz şeyi, kağıt üzerine bir metne, onu da kamerayla çekilen bir görsele dönüştürme yolculuğunu bir yapbozun parçalarını yerleştirmek gibi görüyorum. Aynı his, hukuki bir probleme yaklaşırken de var. Bu anlamda çok benzeştiklerini söyleyebilirim. Onun dışında ahlak-etik-hukuk gibi meseleleri filmlerimde irdelememin hukuk okuduğum için değil, karakterimden kaynaklandığını düşünüyorum. Bunlar her şeyden bağımsız benim hayatımın merkezine aldığım ve üzerine düşündüğüm kavramlar.

\section{İlk filmin Kuyu’nun hikayesine vesile olan neydi? Gerçek bir hikayeyle mi bașladı yoksa daha en baștan bir metafor olarak mı seçildi?}

Şu anda bir fikirden filme giden kişisel yolculuğumun nasıl olduğunu biliyorum, çünkü birçok defa deneyimleme imkânım oldu. Ancak, kuyu benim ilk filmim ve senaryomdu. O yüzden alışılmış bir süreç olmadığını düşünüyorum. Beni etkileyen birkaç meseleden bahsedebilirim. Bunların nasıl birleştiğini ise ben de bilmiyorum. Bir defa imkânsız bir aşk hikayesi yapmak çok istiyordum. Mesela o sıralar izlediğim In the Mood for Love, Baran gibi filmler beni çok etkilemişti çünkü batı kültüründen çok farklı kodları ortaya koyuyordu. Küçük Prens’te okuduğum "Çölü güzel yapan, bir yerlerde bir kuyuyu gizliyor olması..." cümlesi hep kafamda dolaşıyordu. Kuyuya bağıran bir adam ilk baştan beri vardı çünkü ben de bu filmi yaparak kendi kuyuma bağırmak istiyordum. Ayna karşısında hayal-gerçek arasında çekilmiş bir an düşlüyordum. Son ana kadar sakin ilerleyen kameranın bir kırılmayla aniden hareketlenmesini deneyimlemek istiyordum. İnsanın doğayla ilişkisi çok ilgimi çekiyordu, bu yüzden kuyu 
açmak, susuzluk, kuraklık gibi kavramları düşünüyordum. Tabii ki birey olabilmenin, toplumdan sıyrılıp öz benliğini ortaya koyabilmenin ne kadar zor olduğunu düşünüyordum ve bunu kuyunun taşlarını getiren insanlarla anlatmak istiyordum. Bir taşın üstündeki bir kadının elinin çamurdan izinin nasıl biricik olduğunu, ama yağan yağmurun yani köylünün duasının, aslında toplumun beklentilerinin kuraklıkla birlikte bunu da alıp götüreceğini anlatmak istiyordum. Bunların hepsi Kuyu'ya atılmış birer taş gibiydi. Karar vermekte zorlanan bir insanım ama bazı şeyleri hissettiğim anda hemen peşinden giderim. Bu da böyle oldu.

\section{Doğduğun șehir Ușak’tan sonra İstanbul gibi bir metropol ile yüzleșmek seni nasıl etkiledi? Ya sonra İstanbul'dan New York'a geçiş? Neyin iyi, doğ- ru, değerli, hakkaniyetli, adil ve meșru olduğuna dair formel kodlarla ilgili kaymalar ya da değișiklikler hissettin mi?}

Tabii, çok hissettim. Zaten böyle değişimler yaşamamış bir insan bile uzaktan bunların nasıl şeyler olabileceğini analiz edebilir. Ancak, bunlar genelde büyük ve daha objektif meseleler için geçerli. Bunları ben de tahmin edebildiğim için, bu tarz meselelerden çok etkilenmedim. Asıl küçük ve hayatın içinden anlar beni etkiledi. Örneğin yemek yeme meselesi. New York'ta sınıfta yemek yenebiliyor, hatta bu bazen güçlü kokan bir yemek bile olabilir. İstanbul'da, hele Uşak'ta bu saygısızlık olarak algılanabilir. Ben neredeyse böyle bir ortamda hiç yemek yemedim. Çok acıktığım için yediysem de utanarak yemişimdir. İşte insanın hayatının işleyişini etkileyen böyle birçok an oluyor. Bazen bu hayatı zorlaştırıyor. Hele insan ilişkilerini doğrudan etkileyen meselelerde... Türkiye'de kişisel alan diye bir kavram pek yoktur, ya da yeni yeni oluşan bir şeydir. Amerika'da fiziksel/duygusal olarak bir insana ne kadar yaklaşabilirsin bunu öğrenmek zaman alıyor. Ancak, benim şöyle bir avantajım vardı. Ben merak ettiğim her şeyi, tüm iyi niyetimle sorarım. Mesela Afro-Amerikan bir arkadaşım hakkında konuşurken nasıl hitap etmem gerektiğini bilmiyordum. Mesela “black” denir mi denmez mi? Konuşması zor da bir mesele olduğu için kendince çıkarımlar yapmaya çalışyyorsun. Mesela "Black Lives Matter" sloganı var, demek ki deniyor diyorsun. Bir açıdan da politik doğrucu tüm konuşmalarda "Afrikalı-Amerikalı" olarak niteleniyor. İlk başlarda bu işlerin içinden çıkamadım. Sonra, mesela bu soruyu gidip çok yakın bir siyahi arkadaşıma sordum. Onunla bu meselenin tarihi, psikolojik birçok yönünü konuştuk tartıştık. Bilgi edindim. $\mathrm{O}$ da benimle paylaştığı için mutlu oldu. Bunu insanlar yapmıyor çünkü tabular içinde yaşıyorlar. Bir noktadan sonra tabuların üstüne gitmek ve öğrenmek hoşuma gitmeye başladı. İnsanlar da bu yaklaşımımın ne kadar "refreshing” olduğunu ifade ediyorlardı. Özetle soruda geçen ve hayatın akışını etkileyen birçok mesele oluyor. Ben bir şekilde etrafından dolanıp, meselenin toplumsal ve yüzeysel dışını değil de özünü araştırmaya çalışarak ayakta kaldığımı söyleyebilirim.

Ne yapacağına dair tereddüde düştüğünde seni kendi özüne demirleyen, sağa sola yalpalamanı önleyen bir mantran ya da bir referans sitemin var 


\section{mıydı? Veya kendini ipini koparıp yüzmek ve sınırlarını görmek üzere ser- best bıraktığın oldu mu?}

Ben çok basit meselelerde bile kararsız kalabilen biriyim. Bir de gerçekten her şeyle empati kurmaya çalışırım. Bu yüzden farklı duyguları aynı anda yaşayabilir, birçok perspektifi birden hissedebilirim. Bu da karar vermemi daha da zorlaştırır. Bu yüzden kendimce bazı metotlar geliştirmek zorunda kaldım. Zaten birçok kişi de denemeler yapmış. Mesela bir filozof diyor ki eğer iki yol arasında kararsızsan sana yapması zor gelen şey doğrudur, onu seç. Bazı durumlarda bu geçerli olsa da tam anlamıyla katılmıyorum. Hatta bir şeyin kolayı tercih edilebiliyorsa bunun daha verimli olduğunu düşünürüm. En sade, basit, rahat yoldan çözüm ararım. Ama bazen karşılaştığımız şeyler bizi zorluyor. Bunu birkaç aşamada ele alabilirim.

Eğer çok basit ve başkasını etkilemeyen bir meseleyse, mesela çok soğuk bir su var karşımda, atlamak istiyorum, ama ıslanacağım ve hasta olma ihtimalim var. Muhtemelen içimden çok kuvvetli bir atla sesi vardır ve bunu duyarsam hemen atlarım. Burada rasyonel düşüncemi devre dışı bırakabilirim. Hatta bunu bırakmak için komik bir metot geliştirdim. 3-2-1 dediğim anda atlıyorum. Eğer atlamayacaksam demiyorum. Dersem atlıyorum... Burada en kötü hasta olabilirim, hatta belki zatürre olur ölürüm. Ama o sesi dinlemezsem zaten ölmüş bir hayatı yaşarım.

Eğer meselede başka birisi varsa ve karşılıklı hak iddia ediliyorsa, karşıdakinin niyetini anlamaya çalısıırım. Empati yaptığımda ben de yerinde olsam isterdim diyorsam, kesin bir ayrım yoksa, gerekirse taviz verip, feragat etmeyi tercih ederim çünkü kaostan beslenen bir insan değilim. Huzuru, haklı olmaya tercih ederim.

Ancak, çok net bir haklı haksız durumu varsa, ya da karşıdakinde kötü bir niyet, bencilce bir yaklaşım hissediyorsam da ne pahasına olursa olsun, karşımdaki kim olursa olsun, olay ne kadar küçük olursa olsun, sonuçlarını hiç düşünmeden hakkım için savaşırım. Temelde bu dünyaya en çok zararın kendi dünyasının dışından bakmayı beceremeyen egoistlerin verdiğini düşünüyorum ve buradaki hak aramanın kıymetinin, elde edilecek şeyin kendisinden daha büyük olduğunu düşünürüm.

Eğer mesele benimle ilgisizse, örneğin iki kişi arasındaysa, ki çevremdeki birçok insanın bu anlamda hakemlik görevi için bana geldiği olur, bu noktada karar vermek gerçekten çok zor. Burada işte bir hakim gibi olayı her yönüyle inceliyorum.

$\mathrm{Bu}$ meselede bir de şunu söyleyebilirim. Sonuçtan daha önemli şeyin süreç ve deneyim olduğuna inanırsan karar vermek kolaylaşıyor. Mesela kendim ile ilgili bir meselede en kötü ne olabilir dediğim zaman, genelde en kötü ölürüm gibi bir noktaya geliyorum ve o zaman yapmaya karar veriyorum. Çünkü ölüm kaçınılmaz bir şey ama birine haksızlık yapmak çok daha ağır. Eğer başkasıyla ilgili bir mesele ise de insanın hata yapabileceğini aklımdan çıkarmamaya çalışıyorum. Eğer doğru bir yöntemle hatalı bir sonuca varıyorsak, bunun kabul 
edilebilir olduğunu düşünüyorum. Ancak, yanlış bir yöntemle doğru bir sonuca bile varsak, bu kabul edilemez.

\section{Bütün bunlar filmlerine nasıl yansıdı? İlk kısa filminle ilk uzun metraj filmini kıyaslarsan bu açıdan neler söyleyebilirsin?}

İlk kısa filmimi 2015'te çektim ve 2016'da seyirciyle buluştu. Uzun metrajımı ise 2019'da çektim ve pandeminin de araya girmesiyle 2021'de seyirciyle buluştu. Yani ikisi arasında dörtbeş yıllık bir ara var. Bu sürede 20'li yaşlardan 30'lu yaşların başına terfi ettim. Ve hayatımda birçok başka değişim oldu. O yüzden iki filmi çekenlerin aslında farklı insanlar olduklarını söyleyebilirim. Fakat aslında meselenin özüne bakarsak iki filmde de ahlaki açıdan insanı çıkmaza sokan ve sıkıştıran meseleler anlattığımı görüyorum. İki filmin arasındaki en temel fark ise, filmin görsel atmosferine de yansıyan bir farklılık bu, Kuyu'da iki önemli toplumsal mesele arasında pek olay olmaz ve biz karakterin sadece his dünyasını deneyimleriz. Gördüğümüz sanki Ali'nin bedeni değil de duygularıdır, adeta içi dışına çıkmıştır. İŞA'nda ise Kadir sürekli zikzaklar çizer çünkü bir olayın hemen ardından başka bir olay olur ve bu Kadir'i bazı kararlar almaya doğru sürükler. Bu anlamda Kuyu'da sanki bir gölün karşısındaki Ali’ye sandalsız, küreksiz, yüzme bilmediği halde karşıya geç diyoruz. Suyun karşısı görünüyor, geçmek istiyor ama geçemiyor. İSA'nda ise adeta Kadir bir vicdan labirentinin içine giriyor. Ne tünelin sonundaki ışığı görüyor ne de nereye gittiğini biliyor. Sürekli kararlar alarak ilerlemek zorunda kaliyor.

\section{Bu filmlerin ikisinde de karakterler bir çıkmazla karşılaşıyorlar, kendileri için hayal ettikleri hayatla, aidiyetlerinin onlara empoze ettikleri arasında bir seçim yapmaya zorlanıyorlar. Aidiyet senin için önemli mi? Etik ile ahlak arasındaki gerilim ve etkileşimle ilgisi nasıl?}

Aidiyet benim için önemli ama aynı zamanda istediğim hayatı yaşamak da önemli. Zaten bunlar iki güçlü kuvvet olmasa böyle filmler yazamazdım herhalde. Daha önce yaptığım kısa filmlerde de bundan sonra çekmeyi düşündügüum ve şu anda senaryolarıyla uğraştı̆̆ım filmlerde de bu ikilem hep var. Burada bireysel ve toplumsal olan şeyler arasında ayrım yapmak zorunda kalıyoruz ve buradan doğan bir enerji var diye düşünüyorum. Meselenin başka bir boyutu ise ahlak-hukuk çatışmasında çıkıyor. Her zaman hukuki olan ahlaki midir? Değilse hangisini seçmemiz gerekir. Hukuk bize kendisinin tüm değerlerin üstüne koyulması gerektiğini söyler. Yoksa birlikte yaşamak mümkün olmaz çünkü herkesin farklı bir ahlak anlayışı olabilir. Ama bazen hukuk yasa olmaktan öteye gidememiş. Bu durumda hukukun dışına çıkabilir miyiz? Tüm bu süreçte tek öğrendiğim şey şu oldu diyebilirim: Genelleştirmemek gerekiyor. Her ama her mesele biriciktir. Her ne kadar işi pratikleştirmek adına emsal kararlar alınsa da bu hiçbir zaman kesin referans olamaz. Emsal karar uygulanmamasının doğru olduğu birçok olay olabilir. Ben de şöyle düşünüyorum. Belki biricik karakterlerin biricik hikayelerini anlatırsam 
insanlar incelikli bir şekilde meselenin üstüne düşünür. Dediğim gibi, bu filmlerde büyük şeyler söylemiyorum. Cevaplarım yok. Hatta diyelim ki bu filmle empati kuran birisi, buradaki tartışmayı kendi hayatına aktardı. Yine aynı şeyi diyorum, bu film sadece bu filmde geçen olay-zaman-mekân kavramlarıyla değerlendirilebilir. Ama insanlar şunu hissederlerse, ben bu filmdeki bu biricik yaklaşımı başka bir şeye uygularken, yine onun biricikliğiyle düşüneyim. Genellemeyeyim. Her olayı ayrıca araştırayım. Bu herhalde bir filmden fazlasıyla yeterli bir çıkarım olur.

\section{Henüz çekmediğin filmlerinin senaryolarında bu ikilemler hala ana motif olmayı sürdürüyor. Hikayelerini açığa vurmadan, karakterlerin çelişkilere yaklaşımında toplumsal cinsiyetin etkisine dair ipuçları verebilir misin? Dișil karakterlerin eril olanlara göre sınırları aşmaya daha yatkın olduklarını söy- lemek doğru olur mu?}

Tam olarak bunu ben de bilemeyebilirim. Ama şöyle hissediyorum. Bahsettiğimiz Kuyu ve İŞA filmlerinde başroldeki erkek karakterler aslında tartışılan ahlaki meseleyi ortaya atan aktif taraflar değil, biz de zaten film boyunca onların bu duruma karşı reaksiyonlarını izliyoruz. Tereddüt Çizgisi'nde ise ana karakterimiz Canan bu meseleleri ortaya çıkartan aksiyonlar alıyor ve bu noktada en temel ahlaki çıkmazı yaşıyor. Özetle olaylar Ali ve Kadir'in çevresinde yaşanıyor ve onlar meseleyi öğrendikten sonra verdikleri tepkileri izliyorken, Canan bu meseleleri çıkartan kişinin kendisidir diyebilirim. Bunu tabii şimdi konuşurken fark ediyorum ben de. Yoksa yazarken erkek karakterler şöyle olsun, kadın karakterler böyle olsun gibi bir düşünce oluşmuyor. Bunun sebebini belki psikolojik olarak açıklamak mümkün olabilir. Öncelikle söylemeliyim ki, yazdığım tüm karakterler, cinsiyetinden bağımsız, beni yansıtıyor. Kadın karakterler yazarken ise yansıttığım şeyin daha çok benim alteregom olduğunu düşünüyorum. Ve demek ki, benim hayal dünyamda kadınlar sınırları zorlayabilen, sınırları aşacak aksiyonları alan daha cesur insanlar. Şimdi düşündüm de annem aslında benim hayatımda tanıdığım en cesur insan. Mesela ilkokuldan mezun olduğunda köyde ortaokul olmadığı için ailesi eğitimine devam etmesine izin vermemiş, fakat o ailesini ikna etmiş ve tek başına şehre göçmüş, orada bir odada kalarak eğitim hayatına devam etmiş, henüz 11-12 yaşında bir kız çocuğundan bahsediyoruz. Bu benim hayallerimi zorlayan bir kudret. Bir de işin şu boyutu var. Cesaret dediğimiz zaman bazı erkek figürlerinin gelmesi benim için çok sıkıcı. İşin politik ve ahlaki tarafını bırakıyorum, sinematik olarak bile sıkıcı. Hiç feminen erkek karakterler görmemek de aynı şekilde. Belki bu anlamda da toplumsal olarak kabul görenin değil, kendi hayal dünyamın peşinden gidiyorum diyebilirim.

Güncelleme amacıyla sorayım, peki ya söyleșiyi yaptığımız yaz ortasından şimdiki kış başına neler değiști? İki Şafak Arasında filminin festival yolculuğu nasıl geçti? Ildikó Enyedi jüri başkanlığındaki Torino Film Festivali’nde 
En İyi Film ödülü dahil pek çok ödül aldığını biliyoruz. Antalya, Boğaziçi, Free Zone Film Festivali... Daha biz bu yazıyı yollayamadan Malatya'dan da ödül haberleri geldi. Sürekli güncelleyelim dersek yazıyı teslim edemeyeceğiz... ki bu aslında çok güzel bir duygu. Film salonlarda gösterime girdiğinde seyirciyle kuracağı bağı çok merak ediyorum mesela. Bir yerde noktalamamız gerektiğini bilerek bir son söz söylemek ister misin, șimdilik kaydıyla? Belki bir sonraki projene, Tereddüt Çizgisi’ne dair de birkaç cümle eklersin, böylece geçmișle bugün arasında kurduğumuz köprüyü ileriye de uzatmış oluruz. Karar vermekte zorlandığını, ama bir kez ikna olduktan sonra hızla yol aldığını söylemiștin daha önce. Bu özelliğini o güzelim sözcükle tanımlarsak "mütereddit" olma halinin bir sonraki filmine ilham verdiğini söyleyebilir miyiz?

Dediğiniz gibi İki Şafak Arasında ulusal ve uluslararası birçok ödüle layık görüldü². Emeğinizin taktir edilmesi gerçekten güzel bir duygu. Ama galiba en önemlisi filmin izleyen kişiye dokunması. Mesela Torino'daki ödül gerekçesinde jüri başkanı Ildıkó Enyedi'nin açıklaması beni duygulandırdı. ${ }^{3}$

Film ödüller kadar tartıştı̆̆ meseleler üzerinde de seyirciyi bolca düşünmeye ve konuşmaya davet etti diye düşünüyorum. Bu konuda yapılan söyleşilerde sorulan sorular ve filme dair yapılan yorumlar gündelik hayatta etik ve ahlaka dair göndermeler ve alt metinler içeriyor. Benim gözlemlediğim kadarıyla bunun öncelikli sebebi filmin sahneler içinde hiç kesme yapmadan, uzun planlarla, neredeyse reel zaman hissi uyandırarak ve kamera kullanımı objektif bir şekilde seyirciyi tanıklık edecek bir yere konumlandırarak, seyirciyi film boyunca oluşan bütün ikilemleri kendisine sordurtması, seyirciyi düşünmeye sevk etmesidir. Ayrıca, film gerçekçi bir yaklaşımla, olayları çıplak bir şekilde anlatıyor. Bu da Arendt'in hakikatin dizilimi çok hassastır, buraya en ufak müdahale politik bir durum ortaya çıkartır dediği duruma karşılık geliyor diye düşünüyorum. Son olarak, Kadir çok sahici bir karakter. Ve bir turnusol kağıdı gibi... Kadir'in içine düştüğü ahlaki meseleler ile ilgili düşünceler, izleyicinin kendi bakışı ve yargısı ile çok ilişkili... Bu da sinemanın, sanatın en güçlü olduğu alanlar bence. Bir matematiksel formül gibi değil, farklı tepkiler doğurtabilecek bir derinlik, zenginlik...

Tereddüt Çizgisi de bu meseleleri belki de daha da merkeze alacak bir yapım. Burada içerik kadar yaklaşımın da çok önemli olduğunu düşünüyorum. Ben sorduğum soruların cevabını biliyor ve bunu seyirciye anlatıyor gibi bir yerden değil, üzerine düşünmeye değer bulduğum meseleleri seyirciye de davet eden bir yerden çekmeye çalışıyorum. 
1 Söyleşinin orijinal girizgahı ve soruları İngilizce idi. O zamanki giriş paragrafının şu son cümlesini asıl haliyle paylaşmak istedim: "What struck me about his first short Kuyu (The Well, 2015) and his first feature İki Şafak Arasında (Between Two Dawns, 2021) is how he highlights the dilemma between the ethics and the moral without suggesting any easy solution or outcome. We as the spectators find ourselves pondering on the conflict reflecting on similar occasions from our own histories; how in certain turning points in our lives we have had to choose between our personal ethics and the morality of the community, whether that community was the family or ideology, or any system of belief putting us into some kind of kinship with others, be it the profession, the nation or the religion."

$2 \quad$ İki Şafak Arasında Torino Film Festivali En İyi Film Ödülü, 58. Antalya Altın Portakal Film Festivali’nde Dr. Avni Tolunay Jüri Özel Ödülü, En İyi Yardımcı Kadın Oyuncu Ödülü, En İyi Yardımcı Erkek Oyuncu Ödülü ve Cahide Sonku Ödülü; Boğaziçi Film Festivali’nde En İyi İlk Film Ödülü ve En İyi Erkek Oyuncu Ödülü; Sırbistan Free Zone Film Festivalinde En İyi Film Ödülü, Malatya Film Festivali’nde Jüri Özel Ödülü, En İyi Yönetmen Ödülü, Film-Yön En İyi Yönetmen Ödülü kazand.

3 "Olağanüstü senaryo ve yönetmenlik becerileriyle, güldüren, duygulandıran ve şaşırtan bir hikayeyi inandırıcıllkla anlatmayı başaran bir film. A ̆̆ırbaşlılıkla yönetilen bu olgun film, büyü̈k bir yeni yeteneğin habercisi.”

\section{Kaynakça}

Hopewell, J. (2021). “San Sebastian Title 'Between Two Dawns' Confirms Distribution in France, Spain, Releases Trailer (EXCLUSIVE)” https://variety.com/2021/film/festivals/san-sebastian-between-twodawns-trailer-condor-bteam-1235032402/

Succivalli, C. (2021). "A dark and harrowing tale about the extent to which some will use the shortcomings of bureaucracy to escape responsibility, Between Two Dawns is a powerful testament to the importance of pursuing the truth and taking accountability, regardless of the consequences." https://icsfilm.org/ reviews/ssiff-2021-review-between-two-dawns-selman-nacar/

Aftab, K. (2021). “Review:Between Two Dawns”, https://cineuropa.org/en/newsdetail/411386/

Göl, B. (2021). “Altın Portakal Günlükleri 2021 \#1: İki Şafak Arasında ve Zuhal”, https://altyazi.net/yazilar/ seyirdefteri/altin-portakal-gunlukleri-2021-1/

Çevik, C. (2021). “Selman Nacar ile İki Şafak Arasında (2021) Filmi Üzerine Söyleşi”, https://filmhafizasi.com/ selman-nacarla-iki-safak-arasinda-2021-filmi-uzerine-soylesi/

Gazete Duvar, (2021). “Selman Nacar imzalı 'İki Şafak Arasında’ya İtalya'dan En İyi Film ödülü” https:// www.gazeteduvar.com.tr/selman-nacar-imzali-iki-safak-arasindaya-italyadan-en-iyi-film-oduluhaber-1544374 06.12.21

Kundakçı, O. (2021). "Hukuk, etik ve adalet üzerine düşünmeye davet eden bir film: İki Şafak Arasında” https://mag.bilgi.edu.tr/tr/haber/hukuk-etik-ve-adalet-uzerine-bir-film-iki-safak-ar/

Croll, B. (2021). “Turkish Thriller 'Between Two Dawns' Takes Top Award at Torino Film Festival” https:// variety.com/2021/film/news/between-two-dawns-torino-film-festival-1235126528/ 
